still to hear from.) Enthusiasts often make extravagant claims for any treatment that is new, but Dr. D. has had better success than any writer of my acquaintance, and I am sure he deserves it all for he seems to have pinned his faith to serumtherapy alone, and such devotion will assuredly be rewarded. Serum-therapy, still in its infancy, has burdens enough of its own to bear; it seems a pity that it should be loaded down by one of its supposed friends by an article in its behalf as illogical, unreasonable, unscientific and misleading as the one above referred to.

In the State of Indiana, reports of contagious diseases are required by law. Did Dr. D. make said reports and are they safely on tile in the Health Office for future reference, or is the Doctor liable to fine for failure to report them? Such valuable statisties should not be lost. I am somewhat surprised that the Journal admitted the article to its columns. Critic.

\section{Abortion Legalized.}

Clinton, Iowa, Feb. 12, 1896.

To the Editor: It is of interest to us to be posted on the laws and decisions that relate to the profession. A respectable woman of this city called on a female practitioner stating that she had a babe five months old and was again pregnant, and very earnestly desired to be relieved of it. A soft catheter was introduced by a director or sound. The director was withdrawn and the catheter was left behind. After waiting seven or eight days as was proved, the "doctress" called on a medical man telling him she had introduced a soft catheter into a woman's uterus and could not get it out. He told her it would undoubtedly be expelled; if not, to dilate the os and reach for it with a pair of placenta forceps, that he lent her.

In the evening she returned saying she was in trouble and wished him to see the woman. He called at the house and on examination found a length of intestine protruding from the vulva, bearing the marks of the forceps. The patient said she had indured the torments of the damned for a week. The doctor at once called in three other physicians and as soon as convenient made a section, opening the abdomen, finding the catheter among the intestines with abundant signs of inflammation. The uterus was cut through in several places by a curette, through one of which the intestine had been drawn. The woman did not rally from the operation. The coroner was called ; the "doctress" acknowledged the introduction of the instrument, with intent. The verdict was rendered accordingly. Prosecution followed, for malpractice and murder. Being a woman, by a quibble of the law she was admitted to bail. After passing over several terms the case came up for trial. All the facts were proved. Witness for the defense testified that it was done at the woman's urgent request and that due care and diligence had been taken afterward. Counsel for the defense asked the several witnesses if such was not their practice; this was of course overruled, but the benefit of the doubt was put before the jury.

The Judge charged, that if they found the act done in contravention of the law, they were to convict; that if it was done with good intent and that due diligence and care had been used according to the best of her ability they could modify their verdict. The jury retired and on first count stood ten for acquittal. After being out for several hours the refractory ones came over and a verdict was returned of not guilty.

The courtroom was so crowded with women during the trial that the door was closed shutting many of them out. The sentiment among them was that the prosecuting witnesses were addicted to the same practice and were actuated by malice or envy. Mr. Tait was quoted, as having heard that rupture of a diseased uterus had taken place spontaneously. After the trial an autograph letter of Tait was published in the local papers thanking some one for reporting a case of spontaneous rupture of a uterus.
It seems to us that this lets down the bars and gives a quasilegal sanction to the practice. To our credit, however, we may add that the "female practitioner" was not a graduate but had received a license from the State Board of Health of Iowa.

Very truly yours,

M.D.

\section{Diphtheritic Treatment.}

St' PaUl, Neb., Feb. 14, 1896.

To the Editor:-In the Journal of Feb. 1, 1896, we notice an extract from the New York Medical Journal, entitled "Diphtheria sine Antitoxin," credited to Dr. O. B. Douglas. We read this short article with much interest, as it seems to be very nearly a concise reproduction, in meaning at least, of a paper contributed by myself on the treatment of diphtheria, to the Southwestern Medical Gazette for March, 1887, from which the following is quoted. In speaking of the local application of irritants such as tinc. ferri chlorid, we said: "In the first place we get the irritating effect on the diphtheritic abraded surfaces of the fauces and pharynx, which is anything but desirable, as it aggravates the inflammation by its constringent and irritative properties." "I have used locally a very mild gargle or spray of glycerin, carbolic acid and rosewater." "To sum up: My success I have attributed to the use of aconite and belladonna. Their use has been kept up for from one to four days and governed by the urgent symptoms." "The use of aconite in diphtheria will to many appear as a gross error, but when we consider its many desirable properties, as the lowering of temperature, relieving the engorgement of a part by dilating all blood vessels, thus subduing congestion and inflammation, that it is a great eliminant both of liquids and solids (probably in that way acting as a specific in diphtheria by eliminating the poison, and that its depressing effects are overcome by belladonna, its efficacious use seems to me very rational." "Alcoholic stimulants injudiciously administered in diphtheria, is a very routine practice, yet given in appropri ate doses at the proper time, great good may be achieved by their use. In the early stages I venture to say that nine cases out of ten are better off without any stimulants."

Since the above was written we have employed this treatment in upward of six hundred cases, in what was elinically proved diphtheria, with the best possible results. Indeed, the mortality has been so low when the patients were seen early that the use of antitoxin would almost seem superfluous.

While we still employ the aconite-belladonna treatment, yet we must beg to differ with Dr. Douglas. We are thoroughly "converted" to the "faith" in antidiphtheritic serum. Cases in our hands, bacteriologically proved diphtheritic, brought under the influence of this agent, do certainly become convalescent in half the usual time required under any other form of treatment. To my mind, judging from clinical observation, the treatment of diphtheria to-day, without the use of a reliable serum, can not be too highly censured both from a medical and a humane standpoint.

O. Grothan, M.D.

\section{The Character of the Anti-Vivisectionist.}

Cincinnati, Ohio, Feb. 15, 1896.

To the Editor:-Among your comments on the vivisection bill of Mr. McMillan, on p. 297 of the issue of the Journal of February 8 , you make use of the following language :

"In the absence of knowledge of the subject, no one should chide these good hearted men and women, etc.," (no need to quote the remainder). Now my dear doctor, the "good book" (both versions) contains the following passage, "Fools rush in where angels fear to tread," in line with this statement is the fact of experience that ignorance will criticise, while knowledge is weighing evidence. It is also a known fact that an exagger. ated idea of the specific individuals, qualifications and ego, is the prompter for the rendition of judgment by that individual, who 
thinks what he or she thinks, is necessarily lau. It is a wellestablished principle of justice, and common sense as well, that evidence shall precede a verdict, and when we refrain from "chiding" those who reverse the order, we are guilty, at least, "after the fact." I have paid considerable attention to the matter, and my personal experience has shown me that those individuals who deprecate harsh measures with poor " Lo," are in every case, people who are intimately acquainted with the "Leatherstockings" of the novelist, but who have not even a slight acquaintance with a veritable copperskin except as civilized temporarily, for dime museum purposes; and that the most active in behalf of suffering hearts, find no time for efforts in behalf of suffering humanity. There are exceptions possibly, but the above may be formulated in a general law. Why individuals who are intensely humane in one direction are equally cruel in others is a question not difficult to answer, but is not germane to the present subject. True advancement has ever been retarded by the "snap judgment" of the ill-informed, especially those who have a smattering of technicalities and consider them the science. People who offer judgment upon matters which have not been fully considered by them as to pros and cons, should not only be chidden, but forcibly sat down upon in all cases. All persons are "laymen" with regard to any point of which they have not made a definite study, whether it concerns medicine, or political economy, or any other subject, and it is the constant attempt made by many proficient in one matter to assume the judicial ermine as to all matters, which retards the spread of real truth. The foregoing is my "say so" and I presume that having said it, the rest of the world will accept, and keep on judging as usual. Yours truly,

1128 Locust Street, Walnut Hill.

\section{J. Winchell Forbes.}

\section{BOOK NOTICES.}

The Year=book of Treatment for 1896. A Critical Review for Practitioners of Medicine and Surgery. $12 \mathrm{mo}, 476$ pages. Cloth, \$1.50. Philadelphia : Lea Brothers \& Co., Publishers. 1896. This is the twelfth issue of this annual, and it represents the work of twenty-five well-known English contributors, who have culled from contemporaneous medical literature the material for the volume, which thus constitutes a pretty fair epitome of the medical writing of the year.

The Principles of Bacteriology: A Practical Manual for Students and Physicians. By A. C. Аввотт, M.D., First Assistant, Laboratory of Hygiene, University of Pennsylvania, Philadelphia. Third edition, enlarged and thoroughly revised. $12 \mathrm{mo}, 492$ pages, with 98 illustrations, of which 17 are colored. Cloth, $\$ 2.50$. Philadelphia: Lea Brothers \& Co., Publishers.

In our notice of the second edition of this book (see this Journat, Oct. 6,1894 ), we took occasion to say that it was " in every way worthy of the success it had met with, and is destined to become a general favorite."

The edition now before us is gratifying evidence of the cor rectness of the judgment then expressed. It has been brought quite up to date, and will doubtless retain its popularity with students. We commend it as a trustworthy guide.

\section{Studies from the Department of Pathology of the College of Physicians and Surgeons, Columbia College, New York. Vol. IV, for the collegiate year 1894-1895. Reprints.}

Dr. Prudden states in the preface to the volume, that "it has seemed to us that by this form of publication-first the wider circulation which current medical journals afford and the subsequent. grouping together of reprints-the aims of such varied studies are more certainly accomplished than they would be by a special departmental or college publication.".

Our readers will we are sure agree with. Dr. Prudden in his views, and feel that they are the gainers by the prompt trans- mission through the medical press of the conclusions of the laboratory experiments. Those wishing to preserve them separately have the opportunity. The volume is well illustrated. Annual Report of the Supervising Surgeon-General of the Marine:
Hospital Service of the United States for the Fiscal Year 1894. Washington: Government Printing Office. 1895.

This report, which is handsomely illustrated, details the operations of the Service for the year ended June, 1894, and conveys the usual professional information contained in the necropsy reports, and the carefully compiled statistical tables which have constituted a valuable feature of these reports for many years. The operations of the quarantine service for the period mentioned are fully set forth, and the continued evolution of that branch of the Service is manifested in the voluminous reports and regulations reprinted in this volume.

As these operations passed into history nearly two years ago, it is not practicable here to discuss situations which no longer exist, or which may long ago have been modified by changes in regulations. As a contribution to the governmental history of the year 1894, the report is an extremely interesting one.

Transactions of the American Surgical Association. Volume XIII. Edited by DeForest WILlaRd, A.M., Ph.D., M.D., Recor der of the Association. Royal 8vo, cl., pp. 516. Philadelphia: William J. Dornan. 1895.

This volume contains, beside the address of President Dennis, articles by Drs. Gerrish, Homans, Connor, Wight, McGuire, Gerster, White, Mears, Gay, Weir, Deaver and Frese, Carmalt, Sayre, Roberts, Bradford, Park, Mastin, Wharton, Burrell, Packard, Fenger, Weeks, Norris, Mixter, Elliot, MacCormac, Hart, Souchon, Richardson and Bryant, names sufficiently well-known to insure the excellent quality of the essays. The report of the Committee on Necrology includes biographical sketches of the late Prof. William T. Briggs, of Nashville, Prof. Albert B. Miles, of New Orleans, Professor Thiersch, of Leipzig, Mr. A. E. Durham, of London, and Prof. Aristide A. S. Verneuil, of Paris.

The volume is handsomely printed and a worthy companion to its predecessors. The next meeting of the Association will be held at Detroit May 26, 1896, under the presidency of Dr. Tiffany, of Baltimore.

Syphilis in the Middle Ages and in Modern Times. By Dr. F. BURET, Paris, France. Translated from the French, with notes, by A. H. Ohmann-Dumesnin, M.D., Professor of Dermatology and Syphilology in the Marion Sims College of Medicine: Consulting Dermatologist to the St. Louis City Hospital, to the St. Louis Female Hospital; Physician for Cutaneous Diseases to the Alexian Brothers' Hospital; Dermatologist to Pius Hospital, to the Rebekah Hospital, to the St. Louis Polyclinic and Emergency Hospital, etc. Being Volumes II and III of "Syphilis To-day and Among the Ancients," complete in three volumes. $12 \mathrm{mo}$, 300 pages. Extra cloth, $\$ 1.50$ net. Philadelphia: The F. A. Davis Co., Publishers, 1914 and 1916 Cherry Street; Chicago: 9 Lakeside Building.

The interesting historical study begun by Dr. Buret in volume I is continued in volumes II and III here completed. The painstaking labor has comprised an examination of all literature of the subject, and we can well believe, as the author states, three years were consumed in the compilation of the first volume alone.

Dr. Dumesnil has very lucidly and accurately translated the work and thereby laid his countrymen under a permanent obligation. We notice an error in spelling the name of Paulus Egineta on page 3, and repeated twice on page 5.

The material which Dr. Buret has offered as evidence to prove the pre-Columbian existence of syphilis in Europe, can not all be accepted as evidence, but he has produced more than enough that is conclusive, to prove his postulate. After the publication of the manuscripts and documents now unearthed by the author there can no longer be any doubt of the greater antiquity of syphilis on the continent of Europe than old John Astruc was willing to allow it. 